\title{
Are Adopters of Improved Rice Varieties more Productive than Non-Adopters? Empirical Evidence from Northern Ghana
}

\author{
Benjamin Tetteh Anang \\ Department of Agricultural Economics and Extension, \\ University for Development Studies, Tamale, Ghana \\ Email: benjamin.anang@uds.edu.gh \\ DOI//http://dx.doi.org/10.4314/gjds.v16i1.5
}

\begin{abstract}
Technology adoption is important to enhance agricultural productivity and production efficiency of smallholder farmers in developing countries where productivity and efficiency gaps remain high. Technology adoption, however, remains low among smallholders due to a myriad of factors. This study explores the effect of adoption of improved rice varieties on productivity of smallholder farmer households in northern Ghana. The study relies on farm household survey data collected in 2014 using multi-stage stratified random sampling technique. Adoption was modelled using a binary probit model while propensity score matching was used to estimate the average treatment effect of adoption on productivity. The results indicated that adoption of improved rice varieties is influenced by age, sex and years of formal education of the household head, household size, adoption of mechanization, herd size, and the location of the farm. Estimates of the average treatment effect of adoption on productivity indicated that adopters of improved rice varieties were more productive than non-adopters. The study concludes that adoption of improved varieties enhances productivity of smallholder rice farmers. The author therefore recommends public investment in developing and disseminating improved planting materials to smallholder farmers to enhance agricultural productivity, food security and rural incomes.
\end{abstract}

Keywords: Adoption, Smallholder Farmers, Productivity, Propensity Score Matching, Ghana

\section{INTRODUCTION}

Technological improvement remains one of the most important requirements to revamp agricultural production and productivity in Sub-Saharan Africa where 
poverty and food insecurity remain high. Smallholder farmers dominate the agricultural sector in most developing countries including Ghana, and produce the bulk of the agricultural output. Due to high incidence of poverty and liquidity constraints, smallholder farmers tend to rely on less productive traditional farming methods characterised by dependence on weather conditions, low adoption of improved technology and low use of capital inputs (Chirwa, 2005; UNCTAD, 2015). Improving the productivity of farmers therefore remains one of the challenging issues in smallholder agriculture in many developing countries. Several studies show that low adoption of modern (improved) production technologies by smallholder farmers is one of the main factors accounting for the low agricultural productivity and increase in rural poverty in many developing countries (Afolami et al., 2015, Ragasa et al., 2013). As noted by Solomon et al. (2011), technological improvement is the foremost requirement for increasing agricultural productivity and poverty reduction in the long-term.

The low productivity of smallholders calls for measures to provide improved technologies such as improved varieties to crop farmers to boost agricultural production and productivity levels. In Ghana, rice is an important staple and cash crop grown by smallholder farmers, particularly in the savannah zones. National research centres such as the Crops Research Institute (CRI) and the Savanna Agricultural Research Institute (SARI) are responsible for introducing modern rice varieties to farmers to improve productivity. Many improved varieties are currently available to farmers and the rates of adoption are the subject of recent studies by researchers.

As noted by Shideed and El Mourid (2005), farmers consider several factors before deciding to adopt an innovation. These factors include the profitability of the innovation, risk of adoption, the capital requirements, socio-economic conditions of the farmer, government policies relating to agriculture, among others. Due to this, farmers do not fully embrace an innovation from the very beginning and may only allocate a fraction of their land to the new technology. Adoption of an innovation therefore follows a careful assessment of the expected benefits and as such, adoption becomes the final step in the decision process to use the innovation on full scale.

Studies on the adoption of the New Rice for Africa (NERICA) have shown a positive and significant impact on farmers' welfare in Nigeria (Dontsop-Nguezet et al., 2011) and farmers' yield in Cote d'Ivoire (Diagne, 2006). Kijima et al. (2008) found a positive and significant relationship between NERICA adoption and poverty reduction in Uganda. Awotide et al. (2012) also studied the impact of improved technology adoption on rice productivity in Nigeria and found a significant positive 
relationship between adoption of improved seed and rice productivity. Khonje et al. (2015) found that adoption of improved maize was associated with significant gains in incomes, consumption expenditure, and household food security in eastern Zambia. Afolami (2015) found a positive impact of the adoption of improved cassava varieties on the annual income and consumption expenditure of farm households in Nigeria. These studies highlight the important role of technological progress especially improved variety adoption in smallholder agriculture in developing countries.

Studies on improved variety adoption in Ghana include Asante et al. (2011), Akudugu (2012), Owusu and Donkor (2012), Asante et al. (2013), Asante et al. (2014), Bruce et al. (2014), and Donkor et al. (2014). Acheampong and Owusu (2015) found that adoption of improved cassava varieties increased total crop incomes of Ghanaian rural farmers and justified investment in the development of improved technologies to farmers. A study by Morris and Doss (1999) found 54\% improved maize adoption rate, 53\% adoption of crop configuration recommendations and $21 \%$ fertilizer adoption rate among Ghanaian crop farmers. The authors found higher adoption rate for men with the exception of fertilizer adoption. Wiredu et al. (2010) examined the impact of adoption of improved rice varieties on the yield of Ghanaian farmers and found $46 \%$ adoption rate and a positive impact of adoption on crop yield. Wiredu et al. (2014) found $36.7 \%$ adoption rate of NERICA rice in Ghana and a positive impact of adoption on rice income, agricultural income, per-capita income and total annual income.

The main objective of this study is to determine the productivity differences between adopters and non-adopters of improved rice varieties in Ghana. Specifically, the study seeks to assess the factors influencing adoption of improved rice varieties by smallholder farmers in northern Ghana, and the effect of adoption on productivity (yield) of rice. The study is significant because it will shed light on the risk aversion of smallholder farmers in the study area. Risk-averse farmers are more likely to plant traditional varieties that are more adapted to the local environment but give lower yields. Such trends have been reported in studies that indicate low adoption of improved varieties by smallholder farmers (Wiredu et al. 2010; MoFA 2011; Ragasa et al., 2013; Afolami et al., 2015; Salifu et al., 2015).

\section{MATERIALS AND METHODS}

\section{Theoretical Background: Propensity Score Matching}

Most impact evaluation studies in the economic literature have employed propensity scores to estimate the effect of an intervention on either the population 
(average treatment effect, ATE), the untreated sample (average treatment effect on the untreated, ATU) or the treated sample (average treatment effect on the treated, ATT). The average treatment effect on the treated has gained much popularity due to its measurement of the effect of an intervention on the treated (or adopting) category.

Analysing the effect of farmers' adoption decision on farm productivity presents the challenge of selection bias. Selection bias may arise when the choice to adopt improved varieties is non-random. Some unobserved variables associated with adoption may be correlated with the outcome of interest, in this case, productivity. One of the methods used by researchers to control for self-selection in such situations is propensity score matching. Propensity score matching relies on observational data to deal with selection bias. The idea behind propensity score matching is to find a match between adopters (the treated) and non-adopters (the untreated or control) on the basis of their predicted probability of adoption (Rosenbaum and Rubin, 1983; Heckman et al., 1998). Hence the propensity score is the conditional probability of adopting an improved variety based on observational characteristics of the respondents. The propensity score is expressed as in Equation 1 :

$$
p(w)=\operatorname{Pr}\{Z=1 \mid w\}=\mathrm{E}\{Z \mid w\}
$$

where $p(w)$ is the propensity score, $Z=\{0,1\}$ is the treatment variable or the dummy adoption variable, and $w$ is a vector of farmer characteristics.

The estimated propensity scores are then used to derive estimates of the average treatment effect on the treated (ATT). The ATT provides a measure of the effect of adoption on the adopters. Farmers face two potential productivity outcomes $(Y)$ given their adoption status $(Z)$ such that $Y=Y_{0}$ if $Z=O$ and $Y=Y_{1}$ if $Z=1$. $E\left(Y_{1}-Y_{0}\right)$ then denotes the average treatment effect (ATE) while $\mathrm{E}\left\{\left(Y_{1}-Y_{0}\right) \mid Z=1\right\}$ denotes the average treatment effect on the treated (ATT). The ATT can also be presented as $\mathrm{E}\left(Y_{1} \mid \mathrm{Z}=1\right)-\mathrm{E}\left(Y_{0} \mid \mathrm{Z}=1\right)$.

In propensity score matching, the selection equation (in this case the adoption equation) is usually specified as a probit (or logit) model. In this study, the probit adoption model was specified as an index function, with an unobserved continuous variable $\left(Z_{i}^{*}\right)$ as shown in Equation 2:

$$
\begin{aligned}
& Z_{i}^{*}=\gamma_{i} w_{i}+e_{i} \\
& Z_{i}= \begin{cases}1 & \text { if } Z_{i}^{*}>0 \\
0 & \text { otherwise }\end{cases}
\end{aligned}
$$


where $Z_{i}$ represents the decision to adopt an improved rice variety (equals 1 for adopters and o for non-adopters), $w_{i}$ is a vector of farm and household characteristics, $\gamma$ represents a vector of parameters to be estimated and $e_{i}$ is random error.

\section{Empirical Adoption Model}

The empirical adoption model for the study is presented in equation 3.

$$
Z_{i}^{*}=\gamma_{0}+\sum_{i=1}^{11} \gamma_{i} w_{i}+e_{i}
$$

where $Z_{i}^{*}$ is an unobserved continuous variable for adoption of improved rice varieties (where $Z_{i}=1$ if the farmer adopted improved varieties, o otherwise), $w_{1}$ = gender of household head, $w_{2}=$ years of formal education, $w_{3}=$ age of household head, $w_{4}=$ household size; $w_{5}=$ degree of specialization; $w_{6}=$ number of extension contacts; $w_{7}=$ production system (binary): 1 if farm is irrigated, o otherwise; $w_{8}$ = use of farm mechanization: 1 if farm mechanization is used, o otherwise; $w_{9}=$ herd size; $w_{10}=$ regional dummy (binary): 1 if in Northern Region, o otherwise; $w_{11}$ $=$ education and gender interaction term. The $\gamma$ s are unknown parameters to be estimated.

\section{Study Area and Data}

The study was conducted in northern Ghana where smallholder farming is the predominant economic activity. The area experiences a unimodal rainfall regime. The vegetation is the Savanna type dominated by short trees and shrubs. Temperatures are generally high throughout the year, with low humidity level. The raining season spans June to October, followed by a long dry season during which farming activities come to a halt except in places where irrigation is practised. Due to the long dry season, irrigation plays an important role in the farming system, even though these facilities are inadequate. The farming system is dominated by mixed cropping such as cereal-legume intercrop. Monocropping is also practised by some farmers, especially in the case of cash crops. Livestock rearing is an important activity in the area.

Smallholder rice farmers were selected from the three largest irrigation schemes in the study area, namely the Vea and Tono Irrigation Schemes located in the Upper East Region and the Botanga Irrigation Scheme located in the Northern Region. These irrigation schemes are public schemes, under the auspices of the Irrigation Development Authority but with community involvement in the day-to-day activities at the schemes. The community members in the catchment areas of the 
irrigation projects play a role in the allocation of irrigation plots to farmers in the communities where the dams are sited. Irrigation farmers form irrigation water users' associations which ensure that members follow the rules and regulations of the association to enhance farming operations at the irrigation schemes.

Respondents were selected using a multi-stage stratified random sampling technique. This involved the selection of two out of the three regions in northern Ghana according to their importance in rice production followed by the selection of the three major irrigation schemes in the study area. Smallholder rice farmers were then selected from five communities in the catchment area of the irrigation schemes. Equal number of irrigators and non-irrigators were randomly selected to give a total sample of 300 households. The data collection took place between January and April 2014 and covered the 2013/2014 cropping season.

\section{Description of Variables in the Study}

Farm size was measures in hectares of land under rice cultivation while rice output was measured in kilograms. Productivity was measured as output per area of land to give a measure of yield, which reflects land productivity. This partial factor productivity measure is one of the most important factors in agricultural production and has therefore received considerable research attention in the production economics literature.

Sex was measured as a dummy variable with a male farmer coded as 1 and a female as o. This variable is expected to influence adoption decisions of smallholders with male farmers expected to have higher adoption due to their greater control over production resources relative to female farmers. Male dominance in access to and control over production resources in most rural areas of developing countries is documented in the literature (Rahman 2008; Anang et al., 2015) and this contributes to lower adoption rates among female farmers.

The total number of household members was recorded as the household size. This variable is expected to have an indeterminate effect on adoption. Labour-abundant households may face no labour constraints when it comes to adopting improved varieties. On the other hand, labour-abundant households may choose to substitute excess labour for improved technologies especially when faced with liquidity constraints thus negatively affecting adoption. The literature on adoption studies points to inconclusiveness in the direction of effect of household size on adoption of improved technologies by farmers (e.g. Khonje et al., 2015; Sodjinou et al., 2015).

Age was measured in years, and it is anticipated to be positively associated with adoption of modern varieties. Older farmers are expected to be more experienced in 
farming and hence expected to have broader knowledge of production technologies which can enhance adoption. However, it is possible for experienced farmers to become conservative especially if they have previously tried new technologies that were not successful.

The proportion of total household land allocated to rice was measured as the degree of specialization in rice production. Farmers who allocate a greater percentage of their land to rice are expected to have higher adoption, all things being equal. Hence adoption of improved variables is expected to have a positive association with the degree of specialization in rice production.

Similarly, the use of farm mechanization, mainly tractor services, is anticipated to have a positive effect on adoption of modern varieties. Modern varieties and agricultural mechanization both enhance productivity. It is therefore hypothesised that farmers who adopt improved varieties may be productivity-conscious, hence likely to also adopt mechanization, all things being equal.

Furthermore, access to agricultural extension services is expected to have a positive effect on adoption of improved varieties due to the important role of extension agents in disseminating information and innovations to farmers. Contact with extension agents is therefore expected to positively influence adoption of improved rice varieties by smallholder farmers in northern Ghana.

The education variable was included in the model because of its role in enhancing the human capital and ability to make informed production decisions. Education is therefore expected to enhance adoption of improved technologies, all things being equal. Highly educated farmers who can read are more likely to receive information on improved production practices as well as visit extension agents for advice.

Cattle ownership is an indicator of wealth in rural areas. The study hypothesises that wealthier households are more likely to invest in productivity-enhancing technologies such as mechanization, chemical fertilizers and improved seeds. Hence herd size is anticipated to be positively associated with adoption.

Furthermore, access to irrigation is anticipated to enhance adoption of improved rice varieties. This is because irrigation ensures regular water supply for optimal crop yield, and since most improved varieties require relatively more favourable weather conditions and agronomic practices, non-irrigators may be less disposed to plant improved varieties. In other words, rain-fed farmers who are concerned about the possibility of drought are more likely to choose traditional varieties that thrive under less favourable weather conditions. The production system ( 1 for irrigators 
and o otherwise) is therefore hypothesised to influence adoption of improved rice varieties.

The regional dummy variety was included to capture geographical differences in adoption. Even though the two regions, Northern and Upper East, have a savanna vegetation, agricultural land is scarcer in the Upper East Region. Geographical differences are therefore anticipated to be influential in adoption decisions.

\section{RESULTS AND DISCUSSION}

\section{Characteristics of the Respondents}

Table 1 provides the summary statistics of the respondents according to their adoption status. The difference in mean values between adopters and non-adopters is also reported.

Table 1: Summary statistics of the variables in the study

\begin{tabular}{|c|c|c|c|c|c|c|c|c|}
\hline \multirow[t]{2}{*}{ Variable } & \multicolumn{2}{|c|}{$\begin{array}{l}\text { Adopters } \\
(n=200)\end{array}$} & \multicolumn{2}{|c|}{$\begin{array}{l}\text { Non- } \\
\text { adopters } \\
(n=100)\end{array}$} & \multicolumn{2}{|c|}{$\begin{array}{l}\text { Total Sample } \\
(n=300)\end{array}$} & \multicolumn{2}{|c|}{ Mean difference ${ }^{\top}$} \\
\hline & Mean & SD & Mean & SD & Mean & SD & Diff. & $P>|t|$ \\
\hline Productivity (kg/ha) & 2157 & 2017 & 1545 & 1297 & 1953 & 1830 & 612 & $0.006^{t+\dagger}$ \\
\hline Output (kg) & 1874 & 2327 & 1198 & 1467 & 1649 & 2102 & 676 & $0.008^{t+\dagger}$ \\
\hline Farm size (ha) & 0.88 & 0.66 & 0.81 & 0.73 & 0.86 & 0.68 & 0.07 & 0.412 \\
\hline Age (years) & 42.3 & 12.7 & 39.0 & 11.3 & 41.2 & 12.3 & $3 \cdot 34$ & $0.027^{\dagger \dagger}$ \\
\hline $\operatorname{Sex}(1 / 0)$ & 0.83 & 0.38 & 0.69 & 0.47 & 0.78 & 0.41 & 0.14 & $0.005^{t+\dagger}$ \\
\hline $\begin{array}{l}\text { Household size } \\
\text { (number) }\end{array}$ & $9 \cdot 35$ & 6.75 & 10.3 & 8.00 & 9.65 & 7.20 & -0.90 & 0.309 \\
\hline $\begin{array}{l}\text { Degree of specialisation } \\
(\%)\end{array}$ & $47 \cdot 7$ & 26.2 & 40.8 & 22.3 & $45 \cdot 4$ & 25.1 & 8.91 & $0.033^{\dagger+}$ \\
\hline Mechanization (1/o) & 0.75 & 0.44 & 0.46 & 0.50 & 0.65 & 0.48 & 0.29 & $0.000^{t+t}$ \\
\hline Extension visits & $3 \cdot 58$ & $5 \cdot 95$ & 2.76 & 3.20 & $3 \cdot 31$ & 5.21 & 0.82 & 0.199 \\
\hline Regional dummy (1/o) & 0.38 & 0.49 & 0.24 & 0.43 & 0.33 & 0.47 & 0.14 & $0.015^{\dagger \dagger}$ \\
\hline Education (years) & 3.97 & $5 \cdot 36$ & 3.86 & $5 \cdot 35$ & 3.93 & $5 \cdot 35$ & 0.11 & 0.867 \\
\hline $\begin{array}{l}\text { Number of cattle } \\
\text { (number) }\end{array}$ & 2.48 & 4.82 & 1.40 & 3.03 & 2.12 & $4 \cdot 33$ & 1.08 & $0.042^{t+}$ \\
\hline Production system (1/o) & 0.54 & 0.50 & 0.43 & 0.50 & 0.50 & 0.50 & 0.11 & $0.087^{\dagger}$ \\
\hline
\end{tabular}

${ }^{\mathrm{t}}$ signifies the difference in the mean values between adopters and non-adopters. ${ }^{\dagger},{ }^{\dagger \dagger}$ and ${ }^{\dagger+\dagger}$ stand for statistical significance at the $10 \%, 5 \%$ and $1 \%$ level, respectively. (Source: Field Survey, 2014). 
The data indicate that productivity of adopters is significantly higher than for nonadopters. Hence, improved variety adoption is likely to influence land productivity in smallholder rice production in the study area. Adopters also allocated significantly more household land to rice production, which indicates higher degree of specialization in rice production. The decision to adopt improved varieties is therefore expected to be related to the proportion of household land allocated to rice production.

Adopters were significantly older than non-adopters; hence age is likely to affect the adoption decisions of households. Adopters also had more contacts with extension agents but the mean difference was not significant. Furthermore, adopters had significantly more cattle than non-adopters at the 5 percent level. Herd size is therefore anticipated to influence the decision to adopt improved rice varieties among the respondents.

The proportion of adopters who irrigated their farms was significantly higher than non-adopters suggesting that access to irrigation may be important to adoption decision of households. The proportion of adopters who used mechanization was significantly higher than non-adopters. The use of mechanization is therefore anticipated to play a role in adoption of improved rice varieties.

Eighty-three percent of adopters were males while sixty-nine percent of nonadopters were males. This indicates that gender is likely to play a role in adoption decisions. Adopters had slightly fewer household members compared to nonadopters. There was no statistical difference between the number of household members for adopters and non-adopters. Hence, household size is likely to have little effect on adoption.

In terms of regional distribution, thirty-eight percent of adopters were from the Northern Region while twenty-four percent of non-adopters were farmers from the Northern Region. The number of years of formal education was marginally higher for the adopters than non-adopters.

\section{Determinants of Improved Rice Variety Adoption}

To find out the determinants of improved variety adoption the study employed a binary probit model. The results are presented in Table 2. The study showed that the factors influencing adoption of improved rice varieties included the age of the household head, household size, specialization in rice production, mechanization, location of the farm, and herd size. Educational level, gender of the household head and contact with extension agents however had insignificant effect on the adoption of improved varieties. 
Age of the household head had a positive association with adoption of improved rice varieties by farm households in northern Ghana. The estimate of the marginal effect of age on adoption indicates that a unit increase in the age of a farmer leads to an increase in the probability of adoption by 0.006 . The result is consistent with Asante et al. (2014) who found age to positively influence adoption of yam minisett technology in Ghana.

Table 2: Maximum likelihood estimates of the probit model of adoption

\begin{tabular}{|l|l|l|l|l|}
\hline Variable & Coefficient & Std. Error & $P$ - value & Marg. Eff. \\
\hline Age & 0.017 & 0.007 & $0.018^{\dagger \dagger}$ & 0.006 \\
\hline Gender & 0.490 & 0.234 & $0.036^{\dagger \dagger}$ & 0.182 \\
\hline Years of formal education & 0.100 & 0.049 & $0.040^{\dagger \dagger}$ & 0.035 \\
\hline Household size & -0.032 & 0.013 & $0.013^{\dagger \dagger}$ & -0.011 \\
\hline Specialization & 0.005 & 0.004 & 0.149 & 0.002 \\
\hline Mechanization & 0.515 & 0.189 & $0.006^{\dagger \dagger \dagger}$ & 0.187 \\
\hline Extension contacts & 0.016 & 0.020 & 0.408 & 0.006 \\
\hline Regional dummy & 0.511 & 0.228 & $0.025^{\dagger \dagger}$ & 0.171 \\
\hline Herd size & 0.045 & 0.023 & $0.052^{\dagger}$ & 0.016 \\
\hline Production system & 0.124 & 0.173 & 0.473 & 0.044 \\
\hline Gender*Education & -0.091 & 0.051 & $0.071^{\dagger}$ & -0.032 \\
\hline Intercept & -1.320 & 0.412 & $0.001^{\dagger \dagger \dagger}$ & 0.006 \\
\hline
\end{tabular}

${ }^{\dagger},{ }^{\dagger \dagger}$ and ${ }^{+\dagger \dagger}$ stand for statistical significance at the $10 \%, 5 \%$ and $1 \%$ level, respectively. Log-likelihood = 165.8; Positive predictive value $(\%)=76.09$; Negative predictive value $(\%)=64.29$; Percentage correctly

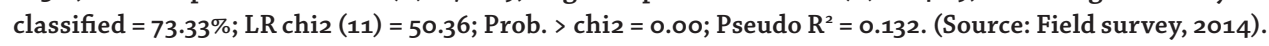

Gender of the household head was positively related to adoption of improved rice varieties by farm households in northern Ghana. The estimate of the marginal effect of gender on adoption indicates that being a male farmer increases the probability of adoption by 0.182 relative to a female farmer. The result is consistent with Tesfaye et al. (2016) in their study of improved wheat technology adoption in Uganda. In most rural communities in developing countries, male household heads tend to dominate in ownership and use of resources thereby enhancing their ability to adopt productivity-enhancing technologies relative to female farmers.

Years of formal education had a positive and significant relationship with adoption of improved rice varieties. The result is in line with other studies (Tiamiyu et al., 2009; Kijima and Sserunkuuma, 2013) and consistent with the view that education enables farmers to access, analyse and interpret information that affect their production activities and farm productivity (Asante et al., 2014). The estimated marginal effect of education on adoption indicated that an additional year of formal 
education increases the probability of adoption by 0.035. Tiamiyu et al. (2009) found the years of formal education to positively influence the adoption of improved rice technologies in Nigeria while Kijima and Sserunkuuma (2013) investigated the adoption of NERICA rice varieties in Uganda and found education to have a positive influence on adoption.

The use of farm mechanization (mainly tractor services) was associated with higher adoption of improved rice varieties by smallholder farmers in the study area. The result indicates that access to mechanised farm machinery enhances the adoption of improved varieties by smallholder farmers. The probability of adoption was 0.187 higher for mechanization users compared to non-users of mechanization. The study hypothesised that farmers' decision to adopt improved variety is expected to be influenced by the decision to adopt mechanization, since both are improved technologies and may play complementary roles in enhancing productivity.

The regional dummy was significant in its effect on adoption. Producers in the Northern Region had higher adoption compared to producers in the Upper East Region. Geographical and soil factors that characterise these locations could be important reasons for the differences in adoption. The probability of farmers in the Northern Region adopting improved rice varieties was 0.171 higher than for producers in the Upper East Region.

Herd size was positive and significant in its effect on adoption suggesting that as herd size increases, the probability of adoption also increases. A unit increase in the number of cattle owned by the household increases the probability of adoption of improved rice varieties by 0.016. Tesfaye et al. (2016) found herd ownership to have a positive and significant effect on adoption of improved wheat technologies in Uganda. The result supports the general expectation that wealthier households are more likely to adopt improved technologies.

Household size was negatively associated with adoption implying that as the size of the household increases, the likelihood to adopt improved rice varieties decreases. A unit increase in the number of household members reduces the probability of adoption by 0.011 . The result is contrary to a priori expectation because adoption of improved technologies is usually associated with increased need for labour to apply fertilizer and perform other agronomic practices. The result agrees with Khonje et al. (2015) in their study of improved maize variety adoption in Zambia but disagrees with Dontsop-Nguezet et al. (2016) in their study on adoption of improved cassava and beans varieties in the Democratic Republic of Congo.

The interaction term for gender and education had a negative but significant relationship with adoption implying that educated female farmers were more 
likely to adopt improved rice varieties compared to educated male farmers. The probability of adopting improved rice varieties was 0.032 higher for educated female farmers than educated male farmers in the study area. The result suggests that enhancing women's access to formal education is likely to enhance the rate of adoption of improved varieties among smallholders.

\section{Estimation of the Average Treatment Effect of Adoption on Productivity}

Table 3 presents the results of the average treatment effect of adoption on farm productivity. In the estimation of the propensity score, the common support restriction was imposed to improve the quality of the matching and hence the robustness of the estimated average treatment effect. Three observations did not meet the common support criterion and were thus discarded. The study employed three different estimation methods to ensure robustness of the estimated treatment effects.

Table 3: Estimates of the average treatment effect of adoption on productivity

\begin{tabular}{|l|l|l|l|l|}
\hline Estimation method & Treated & Control & ATT $^{1}$ & Std. Error \\
\hline Nearest-neighbour matching & 200 & 97 & $488.0^{\dagger \dagger}$ & 212.3 \\
\hline Radius matching & 200 & 97 & $485.0^{\dagger \dagger}$ & 187.3 \\
\hline Kernel matching & 200 & 97 & $406.3^{\dagger \dagger}$ & 194.0 \\
\hline
\end{tabular}

${ }^{1}$ ATT measures the effect of adoption on productivity of the adopters. ${ }^{\dagger+}$ indicates statistical significance at 5\% level. (Source: Field Measurements, 2018).

The results of the study indicate an average treatment effect on the treated ranging between $406.3 \mathrm{~kg} / \mathrm{ha}$ and $488 \mathrm{~kg} / \mathrm{ha}$ of rice as a result of the adoption of improved varieties. Hence, adoption of improved rice varieties enables adopters to significantly enhance their yields by $459.4 \mathrm{~kg} / \mathrm{ha}$ (i.e. average of the three estimated results). The results are fairly robust judging from the results from the different estimation methods and the statistical significance of the estimates.

The results of the study provide sufficient indications that the estimates are fairly robust, thus reflecting the average treatment effect of improved rice variety adoption on farmers' productivity.

\section{CONCLUSION AND POLICY RECOMMENDATIONS}

The study investigated productivity differentials between adopters and nonadopters of improved rice varieties in northern Ghana. The study relied on crosssectional data and applied a binary probit model to investigate the effects of the 
explanatory variables on adoption. Propensity score matching was used to estimate the average treatment effect of adoption on productivity. The study identified the key factors influencing farmers' decision to adopt improved rice varieties to include the age of the household head, household size, specialization in rice production, mechanization, location of the farm, and herd size of the farm household. Estimates of the average treatment effect of adoption on productivity indicated that adopters of improved rice varieties were more productive than non-adopters. On average, adopters of improved rice varieties can potentially increase their productivity by $459.4 \mathrm{~kg} / \mathrm{ha}$. The implication of the results to policy is that developing and disseminating improved varieties to smallholder rice farmers would ensure that on average, rice farmers can increase their production by about $459 \mathrm{~kg}$ per hectare.

The results of the study provide justification for public investment in developing and disseminating improved planting materials to smallholder farmers to enhance agricultural productivity, food security and rural incomes. The study identified the importance of educating female farmers as a means to increase adoption of improved rice varieties among smallholder farmers. Most of the variables influencing adoption of improved rice varieties are socio-economic factors, which policy makers, research centres, scientists and institutions concerned with the dissemination of innovations to farmers should consider when designing technologies for smallholders.

\section{References}

Acheampong, P.A. and Owusu, V. (2015). Impact of improved cassava varieties' adoption on farmers' incomes in rural Ghana. Paper presented at the International Association of Agricultural Economists, 2015 Conference, August 9-14, 2015, Milan, Italy.

Afolami, C.A., Obayelu, A.E. and Vaugha, I.I. (2015). Welfare impact of adoption of improved cassava varieties by rural households in South Western Nigeria. Agricultural and Food Economics, 3(18), pp. 1 - 17.

Akudugu, M.A., Guo, E. and Dadzie, S.K. (2012). Adoption of modern agricultural production technologies by farm households in Ghana: What factors influence their decisions? Journal of Biology, Agriculture and Healthcare, 2(3), pp. 1-13.

Anang, B.T., Sipiläinen, T., Bäckman, S. and Kola, J. (2015). Factors influencing smallholder farmers' access to agricultural microcredit in Northern Ghana. African Journal of Agricultural Research, 10(24), pp. 2460-2469.

Asante, B.O., Otoo, E., Wiredu, A.N., Acheampong, P., Osei-Adu, J. and Nsiah-Frimpong, B. (2011). Willingness to adopt the vine multiplication technique in seed yam 
production in the forest savannah transition agro-ecological zone, Ghana. Journal of Development and Agricultural Economics 3, pp. 710-9.

Asante, B.O., Villano, R.A., and Battese, G.E. (2014). The effect of the adoption of yam minisett technology on the technical efficiency of yam farmers in the forestsavannah transition zone of Ghana. African Journal of Agricultural and Resource Economics 9(2), pp. 75-90.

Asante, B.O., Wiredu, A.N., Dogbe, W., Asuming-Boakye, A., Frimpong, B.N., Haleegoah, J., Nortey, J. and Diagne, A. (2013). Factors affecting the adoption and use of NERICA varieties among rice producing households in Ghana. Asian Journal of Agriculture and Rural Development 3(10), pp. 721-735.

Awotide, B.A., Diagne, A. and Omonona, B.T. (2012). Impact of improved agricultural technology adoption on sustainable rice productivity and rural farmers' welfare in Nigeria: A Local Average Treatment Effect (LATE) technique. A paper prepared for presentation at the African Economic Conference October 30 November 2, 2012, Kigali, Rwanda.

Bruce, A.K., Donkoh, S.A. and Ayamga, M. (2014). Improved rice variety adoption and its effects on farmers' output. Journal of Development and Agricultural Economics, 6(6), pp. 242-248, DOI: 10.5897/JDAE2013.0544.

Chirwa, E.W. (2005). Adoption for fertilizer and hybrid seeds by smallholder maize farmers in Southern Malawi. Development Southern Africa, 22(1), pp. 1-12.

Diagne, A. (2006). Diffusion and adoption of NERICA rice varieties in Cote d'Ivoire. The Development Economics, 44(2), pp. 208-231.

Donkor, E., Owusu, V. and Owusu-Sekyere, E. (2014). Assessing the determinants of adoption of improved cassava varieties among farmers in the Ashanti Region of Ghana. Africa Development and Resources Research Institute Journal, 5(2), pp. 121-133.

Dontsop-Nguezet, P.M., Diagne, A., Okoruwa, V.O. and Ojehomon, V.E.T. (2011). Impact of improved rice technology adoption (NERICA varieties) on income and poverty among rice farming households in Nigeria: A Local Average Treatment Effect (LATE) approach. Quarterly Journal of International Agriculture, 50(3), pp. 267-291.

Heckman, J., Ichimura, H., Smith, J. and Todd, P. (1998). Characterising selection bias using experimental data. Econometrica, 66 (5), pp. 1017-1098.

Khonje, M., Manda, J., Alene, A.D. and Kassie, M. (2015). Analysis of adoption and impacts of improved maize varieties in Eastern Zambia. World Development, 66, pp. 695-706. 
Kijima, Y. and Sserunkuuma, D. (2013). The adoption of NERICA rice varieties at the initial stage of the diffusion process in Uganda. African Journal of Agricultural and Resource Economics, 8(1), pp. $45-56$.

Kijima, Y., Otsuka, K. and Sserunkuuma, D. (2008). Assessing the Impact of NERICA on Income and Poverty in Central and Western Uganda. Agricultural Economics, 38, pp. 327-37.

MoFA (Ministry of Food and Agriculture), (2011). Agriculture in Ghana: Facts and Figures (2010). Statistics, Research, and Information Directorate. Accra, Ghana.

Morris, M. and Doss, C. (1999). How does gender affect the adoption of agricultural innovations? The case of improved maize technology in Ghana: Paper Presented at the Annual Meeting, American Agricultural Economics Association (AAEA), Nashville, Tennessee, August 8-11.

Owusu, V. and Donkor, E. (2012). Adoption of improved cassava varieties in Ghana. Agricultural Journal, 7(2), pp. 146-151.

Ragasa, C., Dankyi A., Acheampong, P., Wiredu, A.N., Chapo-to, A., Asamoah, M. and Tripp, R. (2013). Patterns of Adoption of Improved Rice Technologies in Ghana. Ghana Strategy Support Program, IFPRI Working Paper 3536, July 2013.

Rahman, S.A. (2008). Women's involvement in agriculture in northern and southern Kaduna State, Nigeria. Journal of Gender Studies, 17, pp. 17-26.

Rosenbaum, P.R. and Rubin, D.B. (1983). The central role of the propensity score in observational studies for casual effects. Biometrika, 70 (1), pp. 41-55.

Salifu, H., Alhassan, A. and Salifu, K. (2015). Determinants of farmers adoption of Improved maize varieties in the Wa Municipality. American International Journal of Contemporary Research, 5(4): 27-35.

Shideed, K.H. and El-Mourid, M. (eds) (2005). Adoption and impact assessment of improved technologies in crop and livestock production systems in the WANA Region. The development of integrated crop/livestock production in low rainfall areas of Mashreq and Maghreb Regions (Mashreq/Maghreb Project). ICARDA, Aleppo, Syria.

Sodjinou, E., Glin, L.C., Nicolay, G., Tovignan, S. and Hinvi, J. (2015). Socio-economic determinants of organic cotton adoption in Benin, West Africa. Agricultural and Food Economics, 3, pp. 1-22.

Solomon, A., Bekele, S., Franklin, S. and Mekbib, G.H. (2011). Agricultural technology adoption, seed access constraints and commercialization in Ethiopia. Journal of Development and Agricultural Economics, 3(9), pp. 436-447. 
Tesfaye, S., Bedada, B. and Mesay, Y. (2016). Impact of improved wheat technology adoption on productivity and income in Ethiopia. African Crop Science Journal, 24(1), pp. $127-135$.

Tiamiyu, S.A., Akintola, J.O. and Rahji, M.A.Y. (2009). Technology adoption and productivity difference among growers of New Rice for Africa in Savanna Zone of Nigeria. TROPICULTURA, 27(4), pp. 193-197.

UNCTAD (2015). Commodities and Development Report 2015. Smallholder farmers and sustainable commodity development. NCTAD/SUC/2014/5. Available at unctad.org/en/PublicationsLibrary/suc2014d5_en.pdf. Accessed 20 December 2017.

Wiredu, A.N., Asante, B.O., Martey, E., Diagne, A. and Dogbe, W. (2014). Impact of NERICA adoption on incomes of rice-producing households in northern Ghana. Journal of Sustainable Development, 7(1), pp. 167-178.

Wiredu, A.N., Gyasi, K.O., Marfo, K.A., Asuming-Brempong, S., Haleegoah, J., AsumingBoakye, A. and Nsiah, B.F. (2010). Impact of improved varieties on the yield of rice producing households in Ghana. Paper prepared for the Second Africa Rice Congress, Bamako, Mali, 22-26 March 2010: Innovation and Partnerships to Realise Africa's Rice Potential. 